Check for updates

Cite this: Chem. Commun., 2020, 56, 13193

Received 16th July 2020,

Accepted 29th September 2020

DOI: $10.1039 / \mathrm{d} 0 \mathrm{cc} 04894 a$

rsc.li/chemcomm

\section{Semi-transparent quaternary oxynitride photoanodes on GaN underlayers $\uparrow$}

\author{
Zili Ma, (D) ab Karolina Piętak, (D) ${ }^{c d}$ Jędrzej Piątek, (D) ${ }^{b}$ Justin Reed DeMoulpied, ${ }^{e}$ \\ Anna Rokicińska, (D) Piotr Kuśtrowski, (D) ${ }^{f}$ Richard Dronskowski, (D) ag \\ Sebastian Zlotnik, (i) ${ }^{c h}$ Robert H. Coridan (D) *e and Adam Slabon (iD *b
}

Conformal atomic layer deposition (ALD) technique is employed to make semi-transparent $\mathrm{TaO}_{x} \mathrm{~N}_{y}$, providing the possibility to build semi-transparent oxy(nitride) heterojunction photoanodes on conductive substrates. A generalized approach was developed to manufacture semi-transparent quaternary metal oxynitrides on conductive substrates beyond semi-transparent binary $\mathrm{Ta}_{3} \mathrm{~N}_{5}$ photoanodes aiming for wireless tandem photoelectrochemical (PEC) cells.

A sustainable solution for storing the solar energy in principle can be achieved by PEC technology, which is based on splitting of earth-abundant water into the renewable energy carrier hydrogen and oxygen. ${ }^{1}$ Connecting the photoanode and the photocathode in a stacked configuration enables the devices to maximize sunlight harvesting by using narrow band gap semiconductors in tandem. ${ }^{2}$ Thus, the photovoltage generated in each photoabsorber can be summed to drive water splitting at high efficiency. In the tandem geometry, the photoanode as first photoelectrode absorbs photons of higher energy while the photocathode absorbs the transmitted photons to drive water reduction. ${ }^{3}$ Fig. S1 (ESI $\dagger$ ) depicts a wireless tandem PEC cell configuration, in which the solar photons not absorbed by the semi-transparent photoelectrode at the front side will pass through the intermediate transparent conductive substrate (TCS).

\footnotetext{
${ }^{a}$ Institute of Inorganic Chemistry, RWTH Aachen University, 52056 Aachen, Germany

${ }^{b}$ Department of Materials and Environmental Chemistry, Stockholm University, 10691 Stockholm, Sweden. E-mail: adam.slabon@mmk.su.se

${ }^{c}$ Eukasiewicz Research Network, Institute of Electronic Materials Technology, Wolczynska 133, 01-919 Warsaw, Poland

${ }^{d}$ Warsaw University of Technology, Faculty of Chemistry, Noakowskiego 3, 00-664 Warsaw, Poland

${ }^{e}$ Department of Chemistry and Biochemistry and the Materials Science and Engineering Program, University of Arkansas, Fayetteville, Arkansas 72701, USA. E-mail: rcoridan@uark.edu

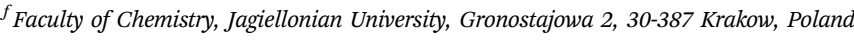
${ }^{g}$ Hoffmann Institute of Advanced Materials, Shenzhen Polytechnic, 7098 Liuxian Boulevard, Nanshan District, Shenzhen, China

${ }^{h}$ Institute of Applied Physics, Military University of Technology, 2 Kaliskiego Str., 00-908 Warsaw, Poland

$\dagger$ Electronic supplementary information (ESI) available. See DOI: 10.1039/d0cc04894a
}

Subsequently, the remaining photons can be harvested by the second photoelectrode with a smaller band gap energy $\left(E_{\mathrm{g}}\right){ }^{4}$

Additionally, the other advantages of the wireless PEC tandem cell are the (i) flexibility in materials selection, (ii) low resistance losses and (iii) high proton conductivity, ${ }^{5,6}$ which target for high solar-to-hydrogen (STH) conversion efficiency. ${ }^{7}$ Furthermore, the wireless configuration is more suitable for industrial manufacturing in comparison to the wired tandem configuration in which the photoabsorbers are connected via an external circuit. ${ }^{8}$ With respect to the TCS materials required for a PEC tandem cell, the most commonly used substrates are transparent conductive oxides (TCOs) such as fluorine/indium doped tin oxide (FTO/ITO) and aluminum doped zinc oxide (AZO). ${ }^{9}$ These TCS materials, however, cannot be applied to materials that require synthetic conditions including ammonia at elevated temperatures ( $>873 \mathrm{~K}$ ). As such, common TCS materials are limited in their implantation for nitrogen-containing photoelectrode materials. ${ }^{10,11}$

For commercialization of PEC technology, it is widely accepted that the STH efficiency needs to be greater than $10 \% .{ }^{12}$ Among the often studied metal oxide-based photoanodes such as $\mathrm{TiO}_{2}, \mathrm{WO}_{3}$, $\mathrm{ZnFe}_{2} \mathrm{O}_{4}, \mathrm{BiVO}_{4}$, the most representative one is the latter, ${ }^{13}$ exhibiting the highest STH conversion efficiency of $3.7 \%$ in a bias-free tandem cell for PEC water splitting. ${ }^{7}$ To achieve higher STH efficiency, the front photoanode in wireless tandem PEC cells has to be semi-transparent. Thus, it must absorb photons with energy larger than its band gap and transmit the remaining photons to the photocathode behind it, avoiding scattering or parasitic absorption of the transmitted light.

Metal nitrides, oxynitrides and N-doped oxides exhibit narrower band gaps than the best-performing oxidic photoanode candidates. An example is $\mathrm{Ta}_{3} \mathrm{~N}_{5}$ with a bandgap of $2.1 \mathrm{eV}$ and that can be obtained by ammonolysis of $\mathrm{Ta}_{2} \mathrm{O}_{5}$. This synthetic approach makes it challenging to produce semi-transparent metal (oxy)nitrides on FTO, because the transparent $\mathrm{SnO}_{x}$ becomes metallic Sn under the nitridation conditions. ${ }^{14}$ It should be noted that fabrication of semi-transparent photoanodes by means of electrophoretic deposition of powder samples displays significant worse mechanical stability under operating conditions. Recently, the 
groups of Hamann ${ }^{10,14}$ and Domen ${ }^{15-17}$ have demonstrated alternative methods to fabricate semi-transparent $\mathrm{Ta}_{3} \mathrm{~N}_{5}$ photoanodes. Although semitransparent films of $\mathrm{Ta}_{3} \mathrm{~N}_{5}$ can reach $6.3 \mathrm{~mA} \mathrm{~cm}{ }^{-2}$ at $1.23 \mathrm{~V} v s$. reversible hydrogen electrode (RHE), ${ }^{17}$ the material suffers from a high onset potential of $0.3-0.8 \mathrm{~V} v s$. RHE, ${ }^{14,18,19}$ which then must be generated by the tandem photocathode for overall water splitting to occur. ${ }^{20}$

The quaternary metal oxynitrides $\mathrm{ATa}(\mathrm{O}, \mathrm{N})_{3}$ display a photocurrent onset at smaller applied potentials and, for several compounds, can potentially exhibit a higher theoretical STH efficiency than the binary $\mathrm{Ta}_{3} \mathrm{~N}_{5} \cdot{ }^{21,22}$ This is due to the narrower band gaps of quaternary metal oxynitrides, depending on the chemical composition and being tunable within the range of 1.7 and $2.4 \mathrm{eV}^{22-24}$ This renders semi-transparent quaternary metal oxynitrides generally as very promising photoanode candidates for PEC tandem cells, which could outperform $\mathrm{Ta}_{3} \mathrm{~N}_{5}$-based devices. So far, semi-transparent quaternary metal oxynitride films have been mainly fabricated by means of reactive radiofrequency (RF) magnetron sputtering ${ }^{25-28}$ or pulsed laser deposition (PLD) ${ }^{29,30}$ on $\mathrm{MgO}$ or $\mathrm{Nb}^{2} \mathrm{SrTiO}_{3}$ substrate. In case of the RF approach, the oxynitride sputtering targets have to be made first with multi-step processes, and harsh conditions (usually up to $1073 \mathrm{~K}$ for film deposition) are required, too. ${ }^{27}$ The development of photoelectrode materials with more narrow band gaps than $\mathrm{Ta}_{3} \mathrm{~N}_{5}$ and hematite is mainly motivated by the higher theoretical light absorption capacity. ${ }^{11}$ Recently, Domen et al. have demonstrated a core-shell heterojunction photoanode of $\mathrm{Ta}_{3} \mathrm{~N}_{5}$-nanorods/ $\mathrm{BaTaO}_{2} \mathrm{~N}$, generating a stable photocurrent owing to efficient generation and extraction of charge carriers. ${ }^{31}$ For the reproducible fabrication of thin films exhibiting controllable thickness on the atomic scale and conformal features, Atomic Layer Deposition (ALD) is a promising technique for the deposition of oxidic precursor layers for subsequent nitridation. ${ }^{32}$

In this communication, we demonstrate the synthesis of semi-transparent quaternary photoanodes on the examples of $\mathrm{SrTaO}_{2} \mathrm{~N}$ and $\mathrm{LaTiO}_{2} \mathrm{~N}$. First, ALD was explored to obtain semitransparent $\mathrm{TaO}_{x} \mathrm{~N}_{y}$ thin films on conductive n-type GaN substrate. GaN was selected as the substrate, because it can maintain chemical stability at high temperature in $\mathrm{NH}_{3}$ without degradation ${ }^{15}$ and under ambient conditions. ${ }^{33}$ Low pressure metalorganic vapor phase epitaxy reactor (MOVPE) was employed to grow unintentionallydoped GaN epitaxial film on double-sided polished $\mathrm{Al}_{2} \mathrm{O}_{3}$ (sapphire) substrates (see ESI $\dagger$ ).

The ALD cycle procedure for $\mathrm{Ta}_{2} \mathrm{O}_{5}$ deposition is illustrated in Fig. 1 (see ESI $\dagger$ ). Nitridation at $1148 \mathrm{~K}$ for $2 \mathrm{~h}$ converted the $\mathrm{Ta}_{2} \mathrm{O}_{5}$ to $\mathrm{TaO}_{x} \mathrm{~N}_{y}$, i.e. $\mathrm{N}$-doped $\mathrm{Ta}_{2} \mathrm{O}_{5}$, which was confirmed by $\mathrm{X}$-ray photoelectron spectroscopy (XPS) (Fig. S2, see ESI $\dagger$ for experimental details). It has been reported that ammonolysis of $\mathrm{Ta}_{2} \mathrm{O}_{5}$ at higher temperatures may yield the binary $\mathrm{Ta}_{3} \mathrm{~N}_{5} \cdot{ }^{34}$ The transmittance of the prepared thin film was evaluated by means of Ultraviolet-visible spectroscopy (UV-vis) as a function of the wavelength (Fig. 2a). After depositing $\mathrm{Ta}_{2} \mathrm{O}_{5}$ onto $\mathrm{Al}_{2} \mathrm{O}_{3} / \mathrm{GaN}$ substrate, the transmittance only decreased slightly because of thin $\mathrm{Ta}_{2} \mathrm{O}_{5}$ layer and its wide band gap. After nitridation, the transmittance of the resulting $\mathrm{Al}_{2} \mathrm{O}_{3} / \mathrm{GaN} / \mathrm{TaO}_{x} \mathrm{~N}_{y}$ thin film decreased to around $70 \%$ at wavelengths above $600 \mathrm{~nm}$.

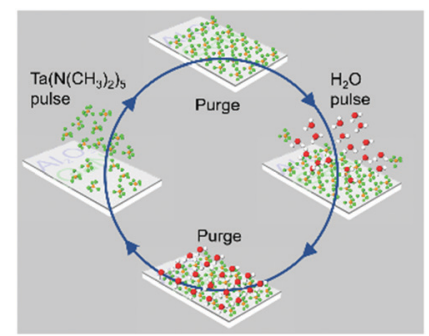

Fig. 1 Scheme of ALD procedure for $\mathrm{Ta}_{2} \mathrm{O}_{5}$ on substrate.
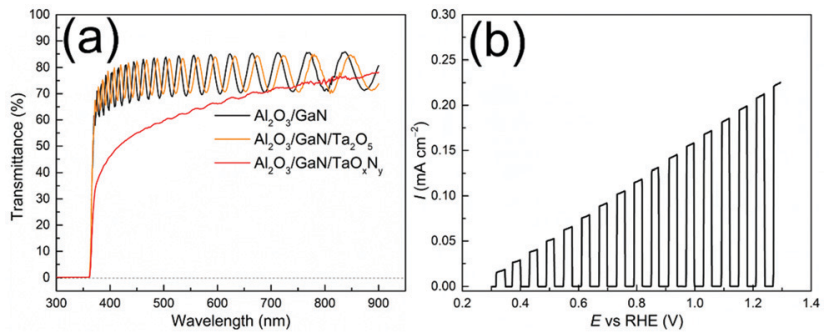

Fig. 2 (a) UV-vis transmittance spectra. (b) LSV of corresponding $\mathrm{Al}_{2} \mathrm{O}_{3} /$ $\mathrm{GaN} / \mathrm{TaO}_{x} \mathrm{~N}_{y}$ photoanode measured in $0.1 \mathrm{M} \mathrm{NaOH}$ under chopped AM $1.5 \mathrm{G}$ illumination (1 sun, $100 \mathrm{~mW} \mathrm{~cm}^{-2}$ ).

The light-absorbing thin film $\mathrm{TaO}_{x} \mathrm{~N}_{y}$ on the $\mathrm{Al}_{2} \mathrm{O}_{3} / \mathrm{GaN}$ substrate was composed of grains with approximately size of $100 \mathrm{~nm}$ due to sintering at high temperature substrate as observed by scanning electron microscopy (SEM) (Fig. S3 in the ESI $\dagger$ ). The grains are distributed uniformly throughout the substrate as observed at the SEM micrograph (Fig. S4, ESI $\dagger$ ). The $\mathrm{Al}_{2} \mathrm{O}_{3} / \mathrm{GaN} / \mathrm{TaO}_{x} \mathrm{~N}_{y}$ photoanode, which was prepared by MOVPE and ALD, generated a photocurrent of $0.21 \mathrm{~mA} \mathrm{~cm}^{-2}$ at $1.23 \mathrm{~V}$ vs. RHE in $0.1 \mathrm{M} \mathrm{NaOH}$ under AM 1.5G illumination (1 sun) as shown in the linear sweep voltammetry curve (LSV, Fig. 2b). The photocurrent is lower than other reported semitransparent $\mathrm{Ta}_{3} \mathrm{~N}_{5}$ film because of smaller thickness and smaller amount of $\mathrm{N}$ incorporation. ${ }^{15-17}$ The photocurrent maintained stable during chronoamperometry (CA) (Fig. S5, ESI $\dagger$ ).

Given the suitability of the deposited GaN layer for electron transport of nitridic light absorbers, we elucidated the possibility to fabricate quaternary metal oxynitrides on the transparent substrate $\mathrm{Al}_{2} \mathrm{O}_{3} / \mathrm{GaN}$. Fig. 3 shows the preparative procedure of semitransparent quaternary oxynitride thin films (see ESI $\dagger$ for details).

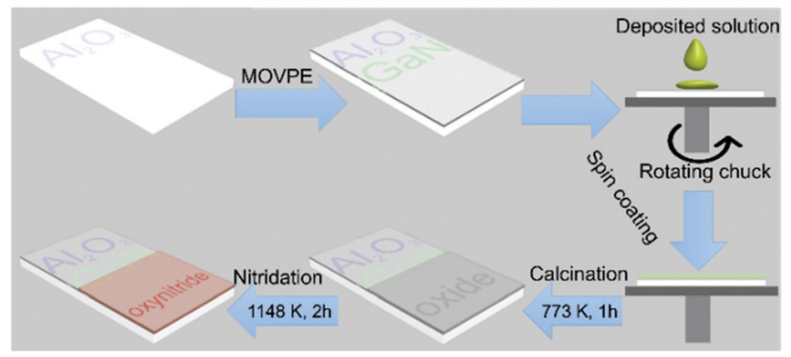

Fig. 3 Schematic illustration of the fabrication procedure for semitransparent quaternary metal oxynitride thin film photoanode on transparent conductive $\mathrm{GaN} / \mathrm{Al}_{2} \mathrm{O}_{3}$ substrate. 
A spin-coating step followed to deposit a sol-gel film on the substrate from a precursor solution containing La and Ti with molar ratio of $1: 1$. Afterwards, the substrate was annealed at $773 \mathrm{~K}$ for $1 \mathrm{~h}$ in air to remove organics from the sol-gel to form the $\mathrm{La}$ and Ti oxide precursor. The oxide was converted to $\mathrm{LaTiO}_{2} \mathrm{~N}$ by nitridation under flowing $\mathrm{NH}_{3}$ and $\mathrm{H}_{2}$ at $1148 \mathrm{~K}$ for $2 \mathrm{~h}$ at a ramping rate of $10 \mathrm{~K} \mathrm{~min}^{-1}$.

$\mathrm{X}$-ray diffraction (XRD) patterns presented in Fig. 4a reveal that the grown $\mathrm{LaTiO}_{2} \mathrm{~N}$ thin film on $\mathrm{Al}_{2} \mathrm{O}_{3} / \mathrm{GaN}$ substrate is of single-phase purity. The $\mathrm{LaTiO}_{2} \mathrm{~N}$ patterns fully match the simulated powder patterns (ICSD 239555). ${ }^{35}$ The UV-vis spectrum (Fig. 4b) also shows an absorption edge at approximately $600 \mathrm{~nm}$, consistent with the $\mathrm{LaTiO}_{2} \mathrm{~N}$ band gap of $2.0-2.1 \mathrm{eV} .^{36}$ The transmittance decreased from $80 \%$ on the $\mathrm{Al}_{2} \mathrm{O}_{3} / \mathrm{GaN}$ substrate to roughly $60 \%$ on the $\mathrm{Al}_{2} \mathrm{O}_{3} / \mathrm{GaN} / \mathrm{LaTiO}_{2} \mathrm{~N}$ substrate for wavelengths above $600 \mathrm{~nm}$. The high transparency (see inset of Fig. $4 \mathrm{~b}$ ) of $\mathrm{LaTiO}_{2} \mathrm{~N}$ is above the threshold for constructing a tandem PEC cell by integration with a photocathode of smaller band gap. The damping-like feature of the spectrum is due to the interference fringes of multiple layers, i.e. $\mathrm{Al}_{2} \mathrm{O}_{3}$, GaN and LaTiO $_{2} \mathrm{~N}^{15}$ The SEM micrograph in Fig. 4c shows the morphology of the prepared $\mathrm{LaTiO}_{2} \mathrm{~N}$ film in the form of a microstructure comprised of nanoparticulate agglomerations that were several hundred nanometers in diameter. A similar morphology is usually obtained for other ceramic thin films prepared by chemical solution deposition (CSD). ${ }^{37}$ The SEM at low magnification (see Fig. S6, ESI $\dagger$ ) demonstrates that the film is uniform and crack-free, the thickness is around $230 \mathrm{~nm}$ from the cross-sectional SEM (Fig. S7, ESI $\dagger$ ). We also synthesized $\mathrm{SrTaO}_{2} \mathrm{~N}$ in order to verify the generality of the CSD-based synthesis for semi-transparent quaternary oxynitride photoanodes. Its XRD pattern (Fig. 4a)
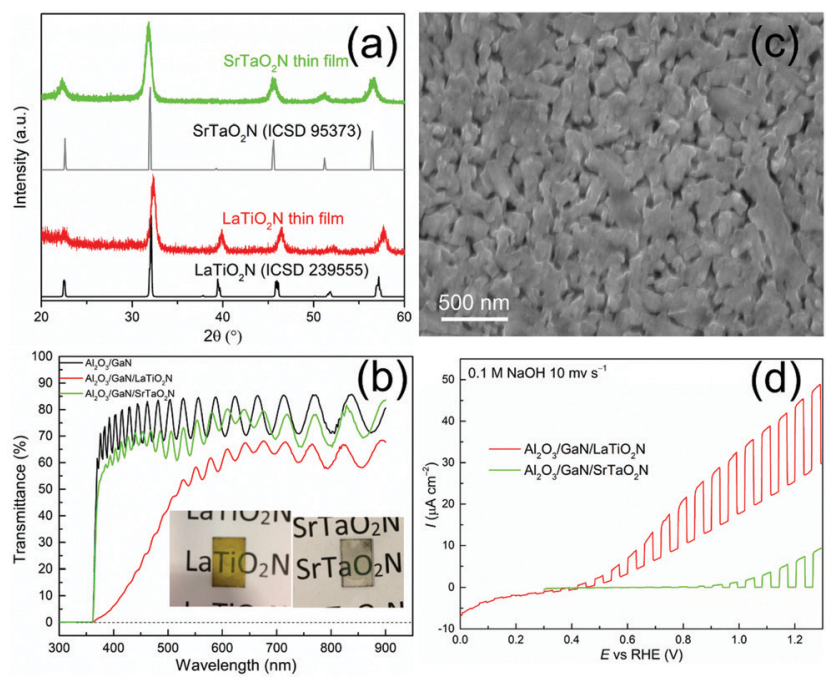

Fig. 4 (a) XRD patterns of $\mathrm{LaTiO}_{2} \mathrm{~N}$ and $\mathrm{SrTaO}_{2} \mathrm{~N}$ film on $\mathrm{Al}_{2} \mathrm{O}_{3} / \mathrm{GaN}$ substrate and simulated patterns (ICSD 239555 and 95373). (b) UV-vis transmittance spectra of $\mathrm{LaTiO}_{2} \mathrm{~N}$ and $\mathrm{SrTaO}_{2} \mathrm{~N}$ film on $\mathrm{Al}_{2} \mathrm{O}_{3} / \mathrm{GaN}$ substrate and the substrate before oxynitride formation. The inset depicts a photographic image of the films. (c) SEM micrograph of $\mathrm{LaTiO}_{2} \mathrm{~N}$ film on $\mathrm{Al}_{2} \mathrm{O}_{3} / \mathrm{GaN}$ substrate. (d) LSV curves of $\mathrm{LaTiO}_{2} \mathrm{~N}$ and $\mathrm{SrTaO}_{2} \mathrm{~N}$ films measured in $0.1 \mathrm{M} \mathrm{NaOH}$ under chopped AM 1.5G simulated solar light $\left(100 \mathrm{~mW} \mathrm{~cm}^{-2}\right)$. confirms the formation of single phase $\mathrm{SrTaO}_{2} \mathrm{~N}$ crystallizing with the tetragonally-distorted perovskite structure in space group I4/mcm (ICSD 95373). ${ }^{38}$ The prepared $\mathrm{SrTaO}_{2} \mathrm{~N}$ thin film also exhibited high transparency (see inset of Fig. 4b). UV-vis measurements showed transmittance of approximately $70 \%$ for wavelengths above $550 \mathrm{~nm}$, which corresponds to the absorption edge of $\mathrm{SrTaO}_{2} \mathrm{~N}^{39}$ The surface of $\mathrm{SrTaO}_{2} \mathrm{~N}$ (SEM, Fig. S8, ESI $\dagger$ ) is smoother than for $\mathrm{LaTiO}_{2} \mathrm{~N}$. However, the thin film thickness is difficult to determine due to strong charging during SEM analysis. These results prove that the CSD-based process can indeed be used for other semi-transparent quaternary oxynitride thin films on transparent $\mathrm{Al}_{2} \mathrm{O}_{3} / \mathrm{GaN}$ substrate.

The critical feature of such prepared electrodes is the transport of electrons through the GaN pathway over the external circuit to the counter-electrode. The PEC water oxidation performances of the prepared $\mathrm{LaTiO}_{2} \mathrm{~N}$ and $\mathrm{SrTaO}_{2} \mathrm{~N}$ films were assessed in 0.1 M NaOH electrolyte ( $\mathrm{pH}$ 13) under simulated sunlight (1 sun, AM 1.5G). Fig. 4d displays the LSV curves measured at a scan rate of $10 \mathrm{mV} \mathrm{s}^{-1}$ under chopped illumination. The $\mathrm{LaTiO}_{2} \mathrm{~N}$ thin film developed a net photocurrent of approximately $20 \mu \mathrm{A} \mathrm{cm} \mathrm{cm}^{-2}$ at $1.23 \mathrm{~V}$ vs. RHE. The photocurrent is comparable with the $\mathrm{LaTiO}_{2} \mathrm{~N}$ film deposited on $\mathrm{MgO} / \mathrm{TiN}$ and $\mathrm{Nb}: \mathrm{SrTiO}_{3}$ substrates via PLD and RF sputtering reported by Lippert $^{29}$ and Domen, ${ }^{26}$ respectively. The dark-current contribution stems from photocorrosion of the oxynitride surface, which is a common phenomenon for unprotected metal oxynitrides and can be suppressed with protective layers. ${ }^{40,41}$ The pristine semitransparent $\mathrm{SrTaO}_{2} \mathrm{~N}$ photoanode, having a slightly larger band gap than $\mathrm{LaTiO}_{2} \mathrm{~N}$, generated a photocurrent of app. $7 \mu \mathrm{A} \mathrm{cm}^{-2}$ at $1.23 \mathrm{~V}$ vs. RHE. Both $\mathrm{LaTiO}_{2} \mathrm{~N}$ and $\mathrm{SrTaO}_{2} \mathrm{~N}$ films show photoresponse at app. $0 \mathrm{~V} v$ s. RHE, indicating relative negative onset potentials (see enlarged view in Fig. S9, ESI $\dagger$ ).

In conclusion, we have successfully fabricated semi-transparent quaternary oxynitride $\mathrm{LaTiO}_{2} \mathrm{~N}$ and $\mathrm{SrTaO}_{2} \mathrm{~N}$ thin films on transparent conductive $\mathrm{Al}_{2} \mathrm{O}_{3} / \mathrm{GaN}$ substrate. PEC measurements confirmed their potential for use as the top photoanode in a PEC water-splitting cell, and the band gaps suggest that they may have higher theoretical STH than $\mathrm{Ta}_{3} \mathrm{~N}_{5}$-based photoanodes. The CSD-based process can be adopted as a general method towards the manufacture of semi-transparent quaternary oxynitride thin films on large scale. Additionally, the conductive $\mathrm{Al}_{2} \mathrm{O}_{3} / \mathrm{GaN}$ substrate have been coated with $\mathrm{TaO}_{x} \mathrm{~N}_{y}$ by means of ALD to yield semi-transparent thin films. Nonetheless, the photocurrent of the quaternary oxynitride thin film is far lower in comparison to their maximum theoretical values. This requires future synthetic strategies for nanostructuring below $100 \mathrm{~nm}$ of the light absorbing metal oxynitride layer and its subsequent semi-transparent catalysts.

A. S. thanks Vinnova (project: C1Bio 2019-03174) for financial support. R. H. C. and J. R. D. are supported by the U.S. DOE, Office of Science, Office of Basic Energy Sciences (no. DE-SC0020301). Z. M. thanks the China Scholarship Council for a PhD scholarship. We thank Wenyan Wang for the access to UV-vis facilities. XPS measurements were done with equipment purchased with the financial support of the EU Regional Development Fund (no. POIG.02.01.00-12-023/08). 


\section{Conflicts of interest}

There are no conflicts to declare.

\section{Notes and references}

1 S. A. Monny, Z. Wang, T. Lin, P. Chen, B. Luo and L. Wang, Chem. Commun., 2020, 56, 9376-9379.

2 J. H. Kim, H. Kaneko, T. Minegishi, J. Kubota, K. Domen and J. S. Lee, ChemSusChem, 2016, 9, 61-66.

3 Q. Zeng, J. Bai, J. Li, B. Zhou and Y. Sun, Nano Energy, 2017, 41, 225-232. 4 M. S. Prévot and K. Sivula, J. Phys. Chem. C, 2013, 117, 17879-17893.

5 K. Walczak, Y. Chen, C. Karp, J. W. Beeman, M. Shaner, J. Spurgeon, I. D. Sharp, X. Amashukeli, W. West, J. Jin, N. S. Lewis and C. Xiang, ChemSusChem, 2015, 8, 544-551.

6 T. Sekimoto, H. Hashiba, S. Shinagawa, Y. Uetake, M. Deguchi, S. Yotsuhashi and K. Ohkawa, Jpn. J. Appl. Phys., 2016, 55, 088004.

7 Y. Chen, X. Feng, Y. Liu, X. Guan, C. Burda and L. Guo, ACS Energy Lett., 2020, 5, 844-866.

8 K. Zhang, M. Ma, P. Li, D. H. Wang and J. H. Park, Adv. Energy Mater., 2016, 6, 1600602.

9 Y. Fang, D. Commandeur, W. C. Lee and Q. Chen, Nanoscale Adv., 2020, 2, 626-632.

10 H. Hajibabaei, O. Zandi and T. W. Hamann, Chem. Sci., 2016, 7, 6760-6767.

11 K. Sivula and R. van de Krol, Nat. Rev. Mater., 2016, 1, 15010.

12 R. J. Detz, J. N. H. Reek and B. C. C. van der Zwaan, Energy Environ. Sci., 2018, 11, 1653-1669.

13 C. R. Lhermitte, A. Polo, L. Yao, F. A. Boudoire, N. Guijarro and K. Sivula, ChemSusChem, 2020, 13, 3645-3653.

14 H. Hajibabaei, D. J. Little, A. Pandey, D. Wang, Z. Mi and T. W. Hamann, ACS Appl. Mater. Interfaces, 2019, 11, 15457-15466.

15 T. Higashi, H. Nishiyama, Y. Suzuki, Y. Sasaki, T. Hisatomi, M. Katayama, T. Minegishi, K. Seki, T. Yamada and K. Domen, Angew. Chem., Int. Ed., 2019, 58, 2300-2304.

16 T. Higashi, H. Nishiyama, Y. Otsuka, Y. Kawase, Y. Sasaki, M. Nakabayashi, M. Katayama, T. Minegishi, N. Shibata, K. Takanabe, T. Yamada and K. Domen, ChemSusChem, 2020, 13, 1974-1978.

17 D. Akagi, Y. Kageshima, Y. Hashizume, S. Aoi, Y. Sasaki, H. Kaneko, T. Higashi, T. Hisatomi, M. Katayama, T. Minegishi, S. Noda and K. Domen, ChemPhotoChem, 2019, 3, 521-524.

18 J. Seo, T. Takata, M. Nakabayashi, T. Hisatomi, N. Shibata, T. Minegishi and K. Domen, J. Am. Chem. Soc., 2015, 137, 12780-12783.

19 Y. He, J. E. Thorne, C. H. Wu, P. Ma, C. Du, Q. Dong, J. Guo and D. Wang, Chem, 2016, 1, 640-655.

20 C. Xiang, A. Z. Weber, S. Ardo, A. Berger, Y. Chen, R. Coridan, K. T. Fountaine, S. Haussener, S. Hu, R. Liu, N. S. Lewis, M. A. Modestino, M. M. Shaner, M. R. Singh, J. C. Stevens, K. Sun and K. Walczak, Angew. Chem., Int. Ed., 2016, 55, 12974-12988.
21 Z. Ma, A. Jaworski, J. George, A. Rokicinska, T. Thersleff, T. M. Budnyak, G. Hautier, A. J. Pell, R. Dronskowski, P. Kuśtrowski and A. Slabon, J. Phys. Chem. C, 2020, 124, 152-160.

22 J. Seo, H. Nishiyama, T. Yamada and K. Domen, Angew. Chem., Int. Ed., 2018, 57, 8396-8415.

23 A. P. Black, H. Suzuki, M. Higashi, C. Frontera, C. Ritter, C. De, A. Sundaresan, R. Abe and A. Fuertes, Chem. Commun., 2018, 54, $1525-1528$.

24 A. Fuertes, Mater. Horizons, 2015, 2, 453-461.

25 T. Wakasugi, Y. Hirose, S. Nakao, Y. Sugisawa, D. Sekiba and T. Hasegawa, ACS Omega, 2020, 5, 13396-13402.

26 C. Le Paven-Thivet, A. Ishikawa, A. Ziani, L. Le Gendre, M. Yoshida, J. Kubota, F. Tessier and K. Domen, J. Phys. Chem. C, 2009, 113, 6156-6162.

27 C. Le Paven, A. Ziani, F. Marlec, L. Le Gendre, F. Tessier, M. Haydoura, R. Benzerga, F. Cheviré, K. Takanabe and A. Sharaiha, J. Eur. Ceram. Soc., 2020, 1-8.

28 C. Le Paven-Thivet, L. Le Gendre, J. Le Castrec, F. Cheviré, F. Tessier and J. Pinel, Prog. Solid State Chem., 2007, 35, 299-308.

29 C. Lawley, M. Nachtegaal, J. Stahn, V. Roddatis, M. Döbeli, T. J. Schmidt, D. Pergolesi and T. Lippert, Nat. Commun., 2020, 11, 1728.

30 F. Haydous, M. Döbeli, W. Si, F. Waag, F. Li, E. Pomjakushina, A. Wokaun, B. Gökce, D. Pergolesi and T. Lippert, ACS Appl. Energy Mater., 2019, 2, 754-763.

31 Y. Pihosh, V. Nandal, T. Minegishi, M. Katayama, T. Yamada, K. Seki, M. Sugiyama and K. Domen, ACS Energy Lett., 2020, 5, 2492-2497.

32 P. J. Reed, H. Mehrabi, Z. G. Schichtl and R. H. Coridan, ACS Appl. Mater. Interfaces, 2018, 10, 43691-43698.

33 H.-D. Xiao, H.-L. Ma, C.-S. Xue, H.-Z. Zhuang, J. Ma, F.-J. Zong and W.-R. Hu, Mater. Lett., 2005, 59, 4041-4043.

34 B. A. Pinaud, A. Vailionis and T. F. Jaramillo, Chem. Mater., 2014, 26, 1576-1582.

35 D. Habu, Y. Masubuchi, S. Torii, T. Kamiyama and S. Kikkawa, J. Solid State Chem., 2016, 237, 254-257.

36 K. Kawashima, M. Hojamberdiev, H. Wagata, K. Yubuta, J. J. M. Vequizo, A. Yamakata, S. Oishi, K. Domen and K. Teshima, J. Phys. Chem. C, 2015, 119, 15896-15904.

37 A. V. Prasadarao, U. Selvaraj and S. Komarnenici, J. Mater. Res., 1995, 10, 704-707.

38 S. J. Clarke, K. A. Hardstone, C. W. Michie and M. J. Rosseinsky, Chem. Mater., 2002, 14, 2664-2669.

39 A. Iborra-Torres, A. N. Kulak, R. G. Palgrave and G. Hyett, ACS Appl. Mater. Interfaces, 2020, 12, 33603-33612.

40 C. M. Leroy, A. E. Maegli, K. Sivula, T. Hisatomi, N. Xanthopoulos, E. H. Otal, S. Yoon, A. Weidenkaff, R. Sanjines and M. Grätzel, Chem. Commun., 2012, 48, 820-822.

41 Z. Ma, T. Thersleff, A. L. Görne, N. Cordes, Y. Liu, S. Jakobi, A. Rokicinska, Z. G. Schichtl, R. H. Coridan, P. Kustrowski, W. Schnick, R. Dronskowski and A. Slabon, ACS Appl. Mater. Interfaces, 2019, 11, 19077-19086. 